\title{
Breves apuntes sobre el sujeto o agente social en tres corrientes del pensamiento sociológico
}

\section{Brief notes on the subject or social agent in three currents of sociological thought}

\author{
Maynor Antonio Mora \\ Escuela de Sociología, Universidad Nacional, Costa Rica \\ mmoraa90@hotmail.com
}

Recibido: 25/09/2019 - Aceptado: 10/11/2020

\begin{abstract}
Resumen
El presente ensayo analiza, de manera muy breve y general, tres corrientes de la teoría sociológica y la filosofía social (las corrientes hermenéutico-constructivistas, las denominadas corrientes críticas, y el estructuralismo posestructuralismo). Se realiza un acercamiento teórico desde el punto de vista del agente o sujeto social. El ensayo tiene un carácter didáctico, comparativo y preliminar respecto de futuras incursiones al tema.
\end{abstract}

Palabras clave: sociología, filosofía social, teoría social, agente, sujeto.

\section{Abstract}

This essay analyzes, in a very brief and general way, three currents of sociological theory and social philosophy (hermeneutic-constructivist currents, so-called critical currents, and poststructuralist structuralism). The theoretical approach is

\section{Maynor Antonio Mora}

\section{()(1)(2)}


carried out from the point of view of the agent or social subject. The essay is didactic, comparative and preliminary in nature regarding future investigations of the subject.

Key words: sociology, social philosophy, social theory, agent, subject.

\section{A modo de introducción}

Desde hace ya bastante tiempo, quizás más de setenta años, las sociologías y las filosofías sociales europeas y también latinoamericanas (sobre Latinoamérica, véase el importante aporte de Enrique Dussel, 1996) vienen dando un giro muy importante al otorgarle, más allá de la filosofía de la conciencia, un papel renovado al estudio del agente o sujeto social dentro de su entramado teórico (aunque éste ya tenía importancia dentro de las teorías críticas de la Modernidad Occidental, entre ellas el marxismo, la Escuela de Fráncfort, la etnología y el psicoanálisis). Lo más importante de este giro es, por un lado, el abandono de la vieja disyunción sujeto [S] / objeto [O], y, por otro, la apertura al paradigma de la participación de los agentes sociales, incluido el sujeto investigador, en el espacio social constituido por el mismo proceso de investigación.

Este breve ensayo analiza tres de dichas corrientes, bajo la hipótesis general de que éstas suponen una ruptura del concepto tradicional de objetividad y de verdad (conceptos clásicos vistos como algo externos al marco de la investigación social). Ya que critican a aquellas concepciones que proponen una diferencia radical entre sujeto y objeto [S / O]. Ya que, en el caso de las corrientes estudiadas, el papel del agente social es fundamental, sin que ello rompa la explicación científica u objetiva de la realidad social.

\section{Las corrientes hermenéutico-constructivistas}

En este primer apartado se analizan las corrientes hermenéuticas y constructivistas como un grupo de teorías que responden a una doble entrada epistemológica. En primer lugar, desde su interés por la construcción del sentido social de la acción y, en segundo, por la deconstrucción de éste. En dichas corrientes, la realidad social y, con ella, el agente, dependen de lo que podemos denominar "sentido socialmente compartido", el cual se construye y "deconstruye". Estos paradigmas definen los siguientes criterios sobre la realidad social: 
- La realidad se la construye socialmente desde diversas formas de percibirla.

- $\quad$ El saber se construye de forma social por los participantes en el proceso investigativo.

- La investigación no es ajena a los valores del investigador.

- Los resultados no pueden ser generalizados en forma ajena al contexto y el tiempo (Ramos, 2015, p. 14).

En el caso del constructivismo, el sujeto se vuelve fundamental, en un sentido distinto a las propuestas de la filosofía de la conciencia. El constructivismo sociológico entiende al agente como sujeto de su propia inserción social. El sujeto no sólo se construye a sí mismo en el marco de las relaciones sociales, sino que esta producción (subjetiva e intersubjetiva) permite la construcción de las denominadas relaciones sociales (Berger \& Luckmann, 1989).

En el caso de la corriente hermenéutica, dichas relaciones constituyen tejidos de sentido a los cuales el investigador tiene acceso siempre y cuando comparta cualitativamente un marco de referencia cultural (un mundo de la vida como lo dirían Husserl y Habermas). En esta línea metodológica el investigador resulta parte del tejido social investigado. Por ello la cercanía de estas corrientes respecto de la Investigación Acción Participativa (IAP). Lo cual supone como efecto: "Emancipar sujetos, identificar el potencial para el cambio. Liberación y empoderamiento para transformar la realidad" (Chavarría-González, 2010, p. 15).

De este modo, dichas teorías se mueven entre el reconocimiento de los procesos de construcción social del sentido y, a su vez, de su interpretación (hermenéutica deconstructiva). Yendo más lejos, podemos decir que estas conforman un proceso de autoconstitución subjetiva permanente por parte de los agentes implicados. Por lo que la investigación hermenéutica (deconstructiva) procede, simultáneamente, a la constitución del sentido (constructivo) y viceversa. 


\section{Las corrientes críticas}

En el caso de las corrientes autodenominadas críticas, tampoco se puede realizar una separación entre lo ontológico y lo agencial subjetivo, ya que éstas le ponen especial énfasis a la transformación social. Ramos (2015, p. 13) señala que las corrientes críticas se definen por medio de los siguientes criterios:

(1) poseer una visión holística y dialéctica de lo que se concibe como real, (2) la relación entre el investigador y el fenómeno de estudio se caracteriza porque todos los sujetos que participan en el proceso investigativo son activos y comprometidos con el cambio social, (3) el proceso investigativo se genera en la acción, es decir, en la práctica, y desde este punto se parte en la comprensión social de las necesidades, problemas e intereses del grupo humano que se encuentra en estudio, (4) la búsqueda de una transformación de las estructuras sociales, basada en la liberación y manumisión de los individuos que conforman el contexto social de investigación

Lo real, según las corrientes críticas, está sujeto a sus condiciones de producción en sentido material y teórico-conceptual. La mayor parte de dichas corrientes tienen un ligamen importante con el Materialismo histórico (Marx, 1971, 1973, 1974; Marx y Engels, 1998), con la Escuela de Frankfurt y la teoría pedagógica de Vygotsky $(1977,1979)$, y, más adelante, con el aporte sustantivo de Paulo Freire $(2000,2001,2005)$.

Las corrientes críticas se orientan en función del carácter desigual de la realidad, así como de la idea central de que, a partir de la acción humana, dicha realidad puede ser transformada. Lo histórico muestra dialécticamente esta particularidad libertaria. El agente social se entiende desde la teoría crítica como un agente que puede desarrollar su propio proceso de liberación a través de la mediación de la investigación social, con el apoyo de los intelectuales críticos (véase concepto de intelectual no orgánico, así como otros conceptos gramschianos) (Gramsci 1973, 1981; Portelli, 1978), en tanto facilitadores del proceso de comprensión de lo real.

Para las perspectivas críticas el acto de conocimiento no se da al margen de un proceso transformador dentro del respectivo marco histórico. 
Esto es de vital importancia porque se comprende, en última instancia, que la distinción objeto / sujeto (propia de las corrientes positivistas y pospositivistas), especialmente el "estructural" funcionalismo de origen estadounidense, no es tal, dándose más bien una relación entre sujetos que produce el reconocimiento liberador (tal y cual lo plantease la Teología de la Liberación en América Latina), como parte del conocimiento construido entre iguales. La relación sujeto objeto $[\mathrm{S} / \mathrm{O}]$ es sustituida por una relación [S/O/S], que da pie a una nueva relación [S"/O"'/S"]. Desde las teorías críticas nos encontramos con una postura que plantea, por ende:

el compromiso (= no neutralidad) de la auténtica ciencia social con los intereses de clase; el carácter histórico de todo proceso social que debe tenerse en cuenta para conocer los eventos concretos y finalmente el principio de totalidad, que parte de los grupos y clases sociales -no de los individuos como el empirismo ${ }^{1}-\mathrm{y}$ que es ajeno a la creación de modelos abstractos y ahistóricos (Alonso 2002, p. 57).

\section{El estructuralismo posestructuralismo}

A su vez, las teorías estructuralistas posestructuralistas parten directa o implícitamente de la categoría de estructura que, de pronto, refiere a un metaconcepto aglutinador de hechos culturales empíricos y, en otros, hechos propios de una emergencia de las realidades sociológicas y antropológicas. Éstas resultan muy valiosas, ya que, por un lado, permiten la descripción de hechos concretos y cotidianos (sobre todo discursivos, en el plano etnológico) y, por otro, porque dan sentido a la realidad social en tanto ella existe según patrones recurrentes (sobrepuestos sobre determinadas estructuras de sentido):

Dicho en pocas palabras, a un primer momento en que la noción de la estructura apareció en el primer plano de la consideración científica suscitando la pacífica confrontación de perspectivas disciplinarias y filosóficas, sucedió un segundo momento en que el recelo de los filósofos se vio alimentado por el desdoblamiento del método en doctrina (Sazbón, 2007, p. 45).

1 "El empirismo da la preeminencia al Objeto: mientras que la variante formalista se la otorga al sujeto" (Alonso, 2002, p. 68). 
La faceta más interesante del estructuralismo posestructuralismo (incluso en los autores más radicales como Derrida y Foucault), es que permite que lo social "hable", aunque sea mediante entramados categoriales autoexplicativos (discursos de los discursos, esto es: [o/o']), que renuncian a la caracterización de un papel "fuerte" de los agentes/sujetos que forman parte de esas mismas regularidades, siendo estos marginales epistemológicamente, pero no así políticamente (Foucault, 2008, 2010). De aquí nace también una noción de verdad:

En la medida en que la conexión entre conceptos y referentes es inescindible de la noción de 'verdad', la caducidad de esta noción en la óptica post-estructuralista es la que marca -junto con otros rechazos- el ascendente predominio de una aproximación nihilista a los antiguos objetos de reflexión. En adelante, el método no será un procedimiento intelectivo para abordar un referente situado en el mundo, sino un ejercicio de deconstrucción de los lenguajes que hablan de él. El 'tipo ideal' del post-estructuralismo supone este rodeo que evita el referente 'mundano', 'objetivo' o 'material' y se encarniza con su versión: para privarla de todo reclamo de validez (Sazbón, 2007, p. 52).

Desde la antigüedad, este planteamiento presupone que, sin la mediación de la abstracción, la comprensión del mundo como un "todo" es imposible para cualquier observador. La filosofía y las ciencias, por lo tanto, buscan los rasgos distintivos y profundos de la realidad, de modo que el "todo" devenga en una explicación plausible del mundo, sin constituirse, por ello, en mera descripción de una cantidad infinita de cosas y hechos. Siendo éste el quid central de toda la ciencia moderna.

El problema, sin embargo, del estructuralismo es que cae en una suerte de idealismo objetivo (desde la definición pre/empírica de la estructura [o/ o']), mediante la que luego intenta dar cuenta de los fenómenos sociales. Siguiendo lo dicho, los conceptos de estructura y modelo son preformas elaboradas en el plano mental (casi platónicamente) que, luego, pretenden explicar la realidad social.

Los dos enfoques aquí analizados pecan, por lo tanto, de dos problemas: por un lado, el idealismo y, por otro, cierta reificación semántica de la estructura que no permite una metaexplicación sustantiva y coherente de los 
fenómenos estudiados. Así, la realidad se diluye por su "insustancialidad" $y$, a su vez, por su reificación epistemológica; dejando por fuera a los mismos sujetos o actores sociales [s/s']; no obstante que, indirectamente, se derive que éstos puedan constituirse y reconstruirse.

Ambas teorías sufren, además, el problema de que se plantean desde la realidad europea, donde las condiciones son históricamente otras, en especial respecto de la realidad latinoamericana. No se deduce de esto un relativismo cultural, "nacionalista" o exageradamente decolonial, intrínseco a dichas teorías, sino sólo una precaución epistemológica referida a una impronta ontológica que profundice adecuadamente cada contexto. Máxime que los estudios de las ciencias sociales, salvo la historia, se concentran en el análisis de la inmediatez, y no tanto de procesos de históricos de largo alcance.

Igualmente, una cualidad básica del estructuralismo es que se centró originariamente en el estudio de procesos transversales en el tiempo-espacio, por ejemplo, en el caso de los estudios etnológicos culturales de Lévi-Strauss. Estos determinaron que la organización social o etnológica se basaba en una serie de patrones recurrentes, cuyos elementos semánticos y pragmáticos constituían una unidad de sentido (lo que luego se denominaría directa o indirectamente "estructura").

La estructura resulta operativa por medio de un conjunto de actos culturales recurrentes, mediante los cuales se fundamentan los comportamientos de los agentes. Pero no interesa la presencia dentro de dicha "estructura explicativa" del individuo y del sujeto. En el caso aún más remoto del pensamiento lingüístico, con Saussure, lo que venía a importar era la organización semiótica de los signos y sus encadenamientos (estructuralismo lingüístico). De ahí la división teórica entre éste, el funcionalismo lingüístico (estudio de las funciones del lenguaje) y finalmente de la semántica generativa de Chomsky, que supera estas dos versiones de la lingüística, analizando incluso la importancia de las preformaciones neuronales del cerebro.

Pero no nos apartemos del tema. Lo importante aquí es la carencia de un mayor énfasis en el sujeto (agente políticamente consciente), que no sea percibida como algo marginal, caso del concepto del ser humano como exterioridad de los denominados "sistemas" sociales (Luhmann, 2006). Aun así, Lévi-Strauss visualiza un humanismo, con sujeto, dentro de su 
propuesta teórica e investigativa. Por lo que los autores mencionados señalen que es en el mismo nacimiento del postestructuralismo cuando surge el interés por las estructuras sociales y, con ello, el abandono del sujeto, bajo el marco de la deconstrucción:

...mientras Lévi-Strauss todavía postulaba el surgimiento de un 'nuevo humanismo' sostenido en los hallazgos de la antropología estructural, Foucault y Derrida rechazan esa posibilidad con energía. Foucault propone despertar del 'sueño antropológico' y pensar sólo 'en el vacío del hombre desaparecido'; Derrida recomienda 'ir más allá del hombre y del humanismo'. En uno y en otro caso, es la herencia de Nietzsche la que se reivindica (Sazbón, 2007, p. 51).

En el estructuralismo posestructuralismo, salvo el brillante aporte de Derrida, no se trata de que los agentes o sujetos escapen de la égida de la acción social. Derrida propone "desestructurar" las categorías occidentales con las que venía pensando durante siglos la filosofía de la conciencia. Derrida deja el camino libre para un potencial proceso de [re] construcción de un nuevo sentido, más allá de las palabras y las categorías introducidas desde los tiempos de Aristóteles. Máxime que estas categorías surgieron como planetas que, de pronto, mediante su gravedad, hicieron girar alrededor de ellas las palabras.

Más o menos es lo que propone Foucault en sus textos clásicos La arqueología del Saber (1979) y en El orden del discurso (2005): Elevar las capas de sentido aparente que se han ido construyendo sobre otras capas, para descubrir no la primacía nominal de ninguna sustancia discursiva, sino de "islas" de sentido autoconstituidas por la misma dinámica histórica. Foucault no es un autor reactivo a la crítica social, como se ha mencionado en algunas ocasiones por interpretaciones apresuradas; al contrario, nos enfrenta con los rostros del discurso, como entidades de naturaleza ética, que requieren de un giro no tanto epistemológico, sino ante todo ético, para que podamos constituirnos efectivamente como animales sociales. Por ello, el interesante aporte de este autor que, a mi criterio, pasa antes que todo por un profundo cuestionamiento ético de la conciencia y no tanto primariamente por la ontología o por la epistemología. Dejamos este debate abierto para otra ocasión. 


\section{A modo de cierre}

Podemos concluir estos breves apuntes con fines didácticos refiriéndonos a la importancia del estudio del agente o sujeto social. La concepción antropológica de éste define el carácter mediante el cual comprendemos los fenómenos sociales, especialmente en su dimensión ontológica, epistemológica, ético / axiológica y política.

En las concepciones problematizadas existe una mayor o menor implicación del sujeto investigador, que desborda igualmente en grados no equivalentes la distinción realidad agente social sujeto investigador, que implica un principio general, a saber, que "conocer supone transformar". Subyace así un planteamiento ético axiológico que se decanta por la vida humana (el ser humano material y concreto) y la existencia de la naturaleza.

Al estudiar las teorías estructuralistas (de carácter semiótico) nos encontramos con la finalización casi definitiva de la filosofía de la conciencia. Nos encontramos, por lo tanto, no con el fin de Dios o del "Hombre" (Ser Humano), sino más bien con el fin del "humanismo clásico" iluminista e incluso griego. Ya que la idea de un agente/sujeto plenamente consciente desaparece (desbordado más bien por el inconsciente como propone Freud y el psicoanálisis en general), para dar lugar a unos "sistemas" semióticos o "estructurales" que explican el fundamento de la sociedad, sin necesidad de un papel primariamente óntico u ontológico de un "agente trascendental".

En el caso específico de las teorías estructuralistas posestructuralistas, el enfoque se orienta a excavar capas del discurso, no en busca de un discurso fundante (cosa que niegan Derrida y Foucault), sino, ante todo, a una operación ética que, como el psicoanálisis, se va a enfrentar con un agujero profundo y fracturado de "sentido", que debe ser develado previo a cualquier reconstrucción ética de lo específicamente humano.

Todo lo cual tiene fuertes repercusiones en la investigación de las ciencias sociales y, en especial, en términos de la teoría y la filosofía sociológica, en relación con los denominados autores clásicos, es decir, los autores que fundaron la disciplina a finales del siglo XIX y principios del siglo XX, como respuesta científica a la racionalización progresiva de la Modernidad. En posteriores ensayos visualizaremos, por lo tanto, este importante efecto teórico. 


\section{Referencias}

Alonso, A. (2002). Metodología. España: Editorial Limusa.

Berger, P. \& Luckmann, T. (1989). La construcción social de la realidad. Argentina: Amorrortu.

Chavarría-González, M. (2010). La dicotomía cuantitativo/cualitativo, falsos dilemas en la investigación social. Actualidades en psicología, 25(112), 1-35. doi: 10.15517/AP.V25I112.70

Dussel, E. (1996). Filosofía de la liberación (4ª edición). Colombia: Nueva América.

Foucault, M. (1979). La arqueología del saber. México: 1979.

Foucault, M. (2005). El orden del discurso. Argentina: Tusquets.

Foucault, M. (2008). Vigilar y castigar. Nacimiento de la prisión. Argentina: Siglo XXI.

Foucault, M. (2010). Nacimiento de la biopolítica. Argentina: Fondo de Cultura Económica.

Freire, P. (2000). Pedagogía del oprimido. México: Siglo XXI.

Freire, P. (2001). Política y educación. México: Siglo XXI.

Freire, P. (2005). Pedagogía del Oprimido. (55ª Edición) México: Siglo XXI.

Gramsci, A. (1973). Maquiavelo y Lenin. Notas para una teoría política marxista. México: Ed. Diógenes S.A.

Gramsci, A. (1981). Antología. Selección, traducción y notas de Manuel Sacristán. México: Siglo XXI.

Luhmann, N. (2006). La sociedad de la sociedad. España: Herder. Recuperado de: https://circulosemiotico.files.wordpress.com/2012/10/ la-sociedad-de-la-sociedad-niklas-luhmann.pdf 
Marx, C. (1971). El método de la economía política. En Elementos fundamentales para la crítica de la economía política. (Borrador) 18571858. México: Siglo XXI.

Marx, C. (1973). El Dieciocho Brumario de Luis Bonaparte. En Obras escogidas. Tomo I. Moscú: Editorial Progreso.

Marx, C. (1974). El Capital. Tomo I. México: Fondo de Cultura Económica.

Marx, K. \& Engels, F. (1998). El manifiesto comunista. En Obras escogidas. Tomo I. Moscú: Editorial Progreso.

Portelli, H. (1978). Gramsci y el Bloque histórico. México: Siglo XXI.

Sazbón, J. (2007). Razón y método, del estructuralismo al post-estructuralismo. Pensar. epistemología, política y ciencias sociales, (1): 4561. Recuperado de: http://www.revistapensar.org/index.php/pensar/ article/view/4

Ramos, C. (2015). Los paradigmas de la investigación científica. Avances en psicología., 23(1), 9-17. doi: 10.33539/avpsicol.2015.v23n1.167

Vygotsky, L. (1977). Pensamiento y lenguaje. Argentina: La Pléyade.

Vygotsky, L. (1979). El desarrollo de los procesos psicológicos superiores. México: Grijalbo. 
